\title{
ASYMPTOTIC AND OSCILLATORY BEHAVIOR OF $n$ TH-ORDER HALF-LINEAR DYNAMIC EQUATIONS
}

\author{
TAHER S. HASSAN AND QINGKAI KONG
}

Abstract. In this paper, we study the $n$ th-order half-linear dynamic equations

$$
\left(x^{[n-1]}\right)^{\Delta}(t)+p(t) \phi_{\alpha[1, n-1]}(x(g(t)))=0
$$

on an above-unbounded time scale $\mathbb{T}$, where $n \geqslant 2$,

$$
x^{[i]}(t):=r_{i}(t) \phi_{\alpha_{i}}\left[\left(x^{[i-1]}\right)^{\Delta}(t)\right], i=1, \ldots, n-1, \text { with } x^{[0]}=x,
$$

$\phi_{\beta}(u):=|u|^{\beta} \operatorname{sgn} u$, and $\alpha[i, j]:=\alpha_{i} \cdots \alpha_{j}$. Criteria are obtained for the asymptotics and oscillation of solutions for both even and odd order cases. This work extends several known results in the literature on second-order, third-order, and higher-order linear and half-linear dynamic equations.

Mathematics subject classification (2010): 34K11, 39A10, 39A99.

Keywords and phrases: Asymptotic behavior, oscillation, higher order, half-linear dynamic equations, time scales.

\section{REFERENCES}

[1] R. P. Agarwal, M. Bohner And S. H. SAKer, Oscillation of second order delay dynamic equation, Canadian Appl. Math. Quart., 13 (2005), 1-17.

[2] R. P. Agarwal, D. O'Regan And S. H. SAKer, Philos-type oscillation criteria for second order half linear dynamic equations, Rocky Mountain J. Math., 37 (2007), 1085-1104.

[3] E. F. BeCKenBach and R. Bellman, Inequalities, Springer, Berlin, 1961.

[4] M. BOHNER AND T. S. HASSAN, Oscillation and boundedness of solutions to first and second order forced functional dynamic equations with mixed nonlinearities, Appl. Anal. Discrete Math., 3 (2009), 242-252.

[5] M. Bohner, L Erbe And A. Peterson, Oscillation for nonlinear second order dynamic equations on a time scale, J. Math. Anal. Appl., 301 (2005), 491-507.

[6] M. Bohner And A. Peterson, Dynamic Equations on Time Scales: An Introduction with Applications, Birkhäuser, Boston, 2001.

[7] M. Bohner And A. Peterson, editors, Advances in Dynamic Equations on Time Scales, Birkhäuser, Boston, 2003.

[8] D. CHEN, Oscillation and asymptotic behavior of solutions of certain third-order nonlinear delay dynamic equations, Theoretical Mathematics \& Applications, 3 (2013), 19-33.

[9] E M. ElabBasy AND T S. HASSAN, Oscillation of solutions for third order functional dynamic equations, Electron. J. Differential Equations, 2010, No. 131, 14 pp.

[10] L. Erbe, J. Baoguo And A. Peterson, Oscillation of $n$ th-order superlinear dynamic equations on time scales, Rocky Mt. J. Math., 41, 2 (2011), 471-491.

[11] L. ERbe, A. Peterson AND S. H. SAKer, Oscillation criteria for second-order nonlinear dynamic equations on time scales, J. London Math. Soc., 76 (2003), 701-714.

[12] L. ERbe, A. Peterson AND S. H. SAKer, Oscillation criteria for second-order nonlinear delay dynamic equations on time scales, J. Math. Anal. Appl., 333 (2007), 505-522. 
[13] L. Erbe, T. S. Hassan, A. Peterson And S. H. Saker, Oscillation criteria for half-linear delay dynamic equations on time scales, Nonlinear Dyn. Syst. Theory, 9, 1 (2009), 51-68.

[14] L. Erbe, T. S. Hassan, A. Peterson And S. H. Saker, Oscillation criteria for sublinear halflinear delay dynamic equations, Int. J. Difference Equ., 3 (2008), 227-245.

[15] L. Erbe, A. Peterson And S. H. SAKer, Hille-Kneser-type criteria for second-order dynamic equations on time scales, Adv. Difference Equ., 2006, Art. ID 51401, 18 pp.

[16] L. ERbe, A. Peterson AND S. H. SAKer, Hille and Nehari type criteria for third order dynamic equations, J. Math. Anal. Appl., 329 (2007), 112-131.

[17] L. ERbe, A. Peterson AND S. H. SAKer, Asymptotic behavior of solutions of a third-order nonlinear dynamic equation on time scales, J. Comp. Appl. Math., 181 (2005), 92-102.

[18] L. Erbe, A. Peterson And S. H. SAKer, Oscillation and asymptotic behavior of a third-order nonlinear dynamic equation, Canad. Appl. Math. Quarterly, 14 (2006), 129-147.

[19] L. ERBE, T. S. HASSAN AND A. PETERSON, Oscillation of third order nonlinear functional dynamic equations on time scales, Differ. Equ. Dyn. Syst., 18 (2010), 199-227.

[20] L. ERBe, T. S. Hassan AND A. Peterson, Oscillation criteria for nonlinear damped dynamic equations on time scales, Appl. Math. Comput., 203 (2008), 343-357.

[21] L. ERbe, T S. Hassan AND A. Peterson, Oscillation of second order functional dynamic equations, Int. J. Difference Equ., 5 (2010), 175-193.

[22] L. ERbe, B. KARPuZ ANd A. Peterson, Kamenev-type oscillation criteria for higher order neutral delay dynamic equations, Int. J. Difference Equ., 6 (2011), 1-16.

[23] L. Erbe, R. Mert, A. Peterson and A. Zafer, Oscillation of even order nonlinear delay dynamic equations on time scales, Czech. Math. J., 63, 138 (2013), 265-279.

[24] L. ERBE AND T. S. HASSAN, New oscillation criteria for second order sublinear dynamic equations, Dynam. Systems Appl., 22 (2013), 49-63.

[25] M. Gera, J. R. Graef AND M. Gregus, On oscillatory and asymptotic properties of solutions of certain nonlinear third order differential equations, Nonlinear Anal., 32 (1998), 417-425.

[26] S. R. Grace, R. P. AgarwaL, M. Bohner And D. O'Regan, Oscillation of second order strongly superlinear and strongly sublinear dynamic equations, Commun. Nonlin. Sci. Numer. Simul., 14 (2009), 3463-3471.

[27] S. R. Grace, R. P. Agarwal AND A. ZAFer, Oscillation of higher order nonlinear dynamic equations on time scale, Adv. Difference Equ., 2012, 2012:67, 18 pp.

[28] S. R. Grace, J. GRaef, S. Panigrahi And E. Tunc, On the oscillatory behavior of even order neutral delay dynamic equations on time scales, E. J. Qualitative Theory of Diff. Equ., 96 (2012), $1-12$.

[29] S. R. GRACE, On the oscillation of nth-order dynamic equations on time scale, Mediterr. J. Math., avaialble on line, DOI: 10.1007/s00009-012-0201-9.

[30] G. H. Hardy, J. E. Littlewood and G. Polya, Inequalities, second ed., Cambridge University Press, Cambridge, 1988.

[31] Z. HAN, T. LI, S. SUN AND M. ZHANG, Oscillation behavior of solutions of third-order nonlinear delay dynamic equations on time scales, Commun. Korean Math. Soc., 26 (2011), 499-513.

[32] T. S. HASSAN, Oscillation of third order nonlinear delay dynamic equations on time scales, Math. Comput. Modelling, 49 (2009), 1573-1586.

[33] T. S. HASSAN, Oscillation criteria for half-linear dynamic equations on time scales, J. Math. Anal. Appl., 345 (2008), 176-185.

[34] T S. HASSAN, Kamenev-type oscillation criteria for second order nonlinear dynamic equations on time scales, Appl. Math. Comput., 217 (2011), 5285-5297.

[35] T. S. HASSAN, Oscillation criteria for second order nonlinear dynamic equations, Adv. Difference Equ. 2012, 2012:171, 13 pp.

[36] T. S. Hass An, L. ERbe AND A. Peterson, Oscillation of second order superlinear dynamic equations with damping on time scales, Comput. Math. Appl., 59 (2010), 550-558.

[37] T. S. HASS AN, L. ERBE AND A. PETERs On, Oscillation criteria for second order sublinear dynamic equations with damping term, J. Difference Equ. Appl., 17 (2011), 505-523.

[38] T. S. HASSAN AND Q. Kong, Oscillation criteria for second order nonlinear dynamic equations with p-laplacian and damping, Acta Math. Sci. Ser. B Engl. Ed., 33 (2013), 975-988.

[39] S. Hilger, Analysis on measure chains - a unified approach to continuous and discrete calculus, Results Math., 18 (1990), 18-56. 
[40] V. KaC And P. Chueng, Quantum Calculus, Universitext, 2002.

[41] B. KARPUZ, Unbounded oscillation of higher-order nonlinear delay dynamic equations of neutral type with oscillating coefficients, E. J. Qualitative Theory of Diff. Equ., 34 (2009), 1-14.

[42] I. T. Kiguradze, 'On oscillatory solutions of some ordinary differential equations', Soviet Math. Dokl., 144 (1962), 33-36.

[43] J. V. Manojlovic, Oscillation criteria for second-order half-linear differential equations, Math. Comput. Modelling, 30 (1999), 109-119.

[44] R. MERT, Oscillation of higher order neutral dynamic equations on time scales, Adv. Difference Equ., 2012, 2012:68, $11 \mathrm{pp}$.

[45] S. H. SAKER, Oscillation criteria of second-order half-linear dynamic equations on time scales, J. Comp. Appl. Math., 177 (2005), 375-387.

[46] T. SUn, W. YU AND H. XI, Oscillatory behavior and comparison for higher order nonlinear dynamic equations on time scales, J. Appl. Math. \& Informatics, 30 (2012), 289-304.

[47] A. Wintner, On the nonexistence of conjugate points, Amer. J. Math., 73 (1951), 368-380.

[48] Z. YU AND Q. WANG, Asymptotic behavior of solutions of third-order nonlinear dynamic equations, J. Comp. Appl. Math., 225 (2009), 531-540. 